\title{
An Integrated Multi-Criterion Decision-Making Analysis to Rank the Pareto-Front Solutions of Time-Cost Trade-Off Problems
}

\author{
Mohammad Azim Eirgash \\ Department of Civil Engineering, Faculty of Engineering, Karadeniz Technical University, Trabzon, Turkey \\ Email address: \\ azim.eirgash@ktu.edu.tr \\ To cite this article: \\ Mohammad Azim Eirgash. An Integrated Multi-Criterion Decision-Making Analysis to Rank the Pareto-Front Solutions of Time-Cost \\ Trade-Off Problems. International Journal of Management and Fuzzy Systems. Vol. 7, No. 2, 2021, pp. 28-40. \\ doi: $10.11648 /$ j.ijmfs.20210702.12
}

Received: July 15, 2021; Accepted: July 24, 2021; Published: July 29, 2021

\begin{abstract}
In the construction management planning, both the client and the contractor are interested in completing the project within the planned schedule. To achieve it, time-cost trade-off problem (TCTP) is carried-out to obtain the optimal set of time-cost alternatives. Although Pareto front solutions are not preferred to each other, the decision-maker (DM) has to choose only the best solution. The DMs are neither well-educated nor have adequate knowledge to make proper decisions. Thus, such a choice has to be made through additional preferences not included in the original formulation of the optimization problem. To better support the meta-heuristic optimization outputs, in this paper, an integration of entropy weight, simple additive weighting (SAW), and technique for order of preference by similarity to ideal solution (TOPSIS) are modelled to solve the MCDM problem, while the Teaching Learning Based Optimization (TLBO) algorithm is applied to solve the proposed multi-objective decision-making model. In the proposed model, the weights selections are done objectively to demonstrate the variation on the rankings of MCDM approaches. While the entropy technique served to determine the weight of the criteria from the original matrix data objectively and the TOPSIS method is employed to rank the alternative Pareto front solutions. The proposed methodology is utilized to rank a set of Pareto optimal solutions of well-known optimization problems. The obtained results are compared against the rankings provided by (SAW) approach to investigate the efficiency of the proposed model. Results demonstrate that the present model can be a favorable decision-making model for the decision-makers.
\end{abstract}

Keywords: Time-cost-trade-off Problems, Pareto-front, Construction Management, TOPSIS

\section{Introduction}

In construction management field, optimization is a very useful tool to meet the desired objectives under the given constraints. In this field, somewhere in the region of every real-world problem includes simultaneous optimization of often competing objectives. Both the client as well as the contractor tend to have the objectives e.g. time, cost or other targets efficiently be accomplished on schedule. Among all the construction resources time and cost are the most essential key project parameters. Thus, the planners have to execute analysis to compromise between time and cost of a project which is known as time cost trade-off problem (TCTP) in the literature. In the multi-criteria decision analysis, the ranking problem has been evolved throughout the previous 20 years. In any case, there are no general methodologies. Each technique involves its individual principle and standards. The most favorable approach is to present its own priority. One of the fundamental and most straightforward multi-criteria decision making procedures is sum of the weight calculation model. In this method, a weight is appointed to every rule to exhibit its significance.

Another significant basic decision-making is the analytic hierarchy process (AHP). It is expected that AHP to be one of the MCDM approach, and Thomas L. Saaty is the one by whom mathematical theory was firstly developed. Interactions 
among the objectives, basic criteria, sub-criteria, and alternatives of the problem is demonstrated by this method. Besides, qualitative and quantitative variables together considering the priorities of the group or individual in decision making process is evaluated using mathematical methods. Moreover, in a decision problem, evaluates the plenty of options based on more than one criteria, together with qualitative ones, if any, and ranks the most crucial options according to their importance. AHP proposes a process for measuring the consistency of these comparisons. With the resulting Consistency Ratio (CR), it is possible to test the consistency of the found priority vector and thus pairwise comparisons between factors.

The technique for order preference by similarity to the ideal solution (TOPSIS) was first proposed by Hwang and Yoon [1] TOPSIS method assigns the priori weights that are specified beforehand by the decision-maker. The core of the ranking for this method lies in the distance of alternatives to the ideal and anti-ideal solutions. An alternative that is "closer to ideal" and "farther from anti-ideal" holds a higher ranking. However, TOPSIS produces an inconsistent ranking between the "closer to ideal" and "farther from anti-ideal." Many authors have used TOPSIS as a decision-making method e.g., Chen, [2]; Gumus, [3] and Yong, [4].

In the outranking methods, the alternatives are ranked according to a pairwise comparison, and if enough evidence exists to judge if alternative $a$ is more preferable than alternative $b$, then it is said that alternative $a$ outranks the b. ELECTRE Roy [5] and PROMETHEE are based on this approach of ranking.

Reviewing literature Multi-objective optimization can be integrated with MDCM to solve multi-criteria decision making problems to facilitate the process for the decision makers. To this end, two general approaches are basically available Chaudhuri and Deb [6]. In the first approach Bazargan-Lari [7-9] multiobjective optimization is first used to obtain the set of Pareto-optimal solutions and then MCDM methods are used to select the compromise solution.

Chaudhuri and Deb [6] proposed a novel approach to combine MCDM and multi-objective optimization that allows investigation of the different regions of the Pareto-optimal frontier first and then searching through these regions as many times as required to satisfy the decision makers.

Eirgash and Dede [10] utilized the TLBO algorithm in which multi teachers are assigned to various student groups and with the adaptive teaching factor. In this study, MAWA is used as approach incorporated with the algorithm. Furthermore, 18 and 63 activity projects were used as an empirical examples to obtain successful Pareto front solutions. Comparing to the existing literature studies, the current study obtained better results. In addition, it achieves the global optimum results in 18-activity projects and obtained optimum results in 63-activity projects.

Toğan and Eirgash [11] proposed the TLBO-MAWA model for optimization and tested the performance of the method on projects with 7,18 and 63 activities. As a result, it has been found that TLBO method has achieved successful results and has a certain potential in producing better solutions. Furthermore, it is presented that the simplicity of TLBO algorithm is the strength of the method.

Being first introduced by [12], $\mathrm{Ng}$ and Zhang [13] used an evolutionary-based optimization algorithm known as the ant colony (ACO) to analyze the multi-objective TCT problem. They concluded that ACO can solve TCT problem with less computational effort.

Al-Zarrad and Fonseca [14] examined the fuzzy activity-based costing method that takes into account uncertainty in time and cost values. According to the results of the analysis, the established model is easy to apply, gives better results than GA, and can increase the reliability of time-cost trade-off decisions. They stated that this would help to establish a more reliable program and reduce the risk of over budget or projects running behind the program.

It is observed that the proposed sole MAWA-TLBO algorithm is not able to find out the optimum solutions for the 18 -activity and a more complex 63 -activity problems [15].

By reviewing the technical literature, it can be recognized that most preferred metaheuristic algorithms to solve DTCTP problems are GA, ACO, PSO, and improved or hybrid versions of them. However, many other optimization methods were applied to the problems encountered in different engineering fields. One of them is Teaching-Learning Based Optimization (TLBO) [16]. TLBO also largely being used in trading off construction management problems. [17].

Furthermore, as construction projects become larger and more diversified, the complexity in analyzing those projects manually becomes a nightmare and the use of software packages becomes inevitable. Thereby, to assist the process well-known software of MATLAB, and Microsoft Excel computer programs were utilized for calculations. The noteworthy contribution of this study is outlined as follows. To the best of author's knowledge, ranking of Pareto optimal solutions Via integrated MCDM with the MODM in construction management has not been addressed in the literature so far.

The paper is arranged as follows. In the next section a short introduction to the Pareto optimality is represented. The main principles of the TOPSIS and the SAW methods are explained in section 3. The proposed algorithm of the trade-off ranking is given in Section 4. In Section 5, different test cases are considered. The conclusions are provided in the final section.

\section{Pareto Optimality}

The employed multi-objective TLBO algorithm can find out the Pareto front solution which provides flexibility to planners and decision makers in making efficient time-cost decisions. By and large, the Pareto front solutions are the non-dominated solutions in multi-objective optimization which are not preferable compared to one another.

The domination concept defined as: design A dominates design $\mathrm{B}$ if it is better in at least one criterion and not worse in all other objectives. The non-dominated set of the entire feasible decision space is called the Pareto-optimal set. The 
boundary defined by the set of all point mapped from the Pareto optimal set is called the Pareto optimal front. Comparison steps of non-dominating sorting so called Pareto-optimal solution is the following:

For two solutions $\mathrm{A}$ and $\mathrm{B}, \mathrm{A}$ is non-dominated if:

Cost (A) $<=$ cost (B) \& Duration (A) $<$ duration (B)

Or

Cost (A) $<$ cost (B) \& Duration (A) $<=$ duration (B)

Sorting based on duration

If $(\operatorname{Cost}(A)=\operatorname{Cost}(B) \&$ Duration $(A)=$ duration $(B)$

$\{$ Remove $(\mathrm{B})\}$

Else if $(\operatorname{Cost}(\mathrm{A})<=\operatorname{cost}(\mathrm{B})) \&$ Duration $(\mathrm{A})<$ duration (B) Or

Cost (A) $<$ Cost (B)) \& Duration (A) $<=$ duration (B))

$\{$ Remove (B) $\}$

Else

$\{$ Remove (A)\}

It can be sorted based on the total cost as well. But it doesn't make a big difference which sorting we use.

\section{Research Methodology}

The main objectives of this study is to propose an integrated approach, which uses the MCDM techniques into the body of TLBO algorithm for the selection of Pareto-optimal solutions in TCTP problems, and to compare the findings of TOPSIS with SAW techniques. In four basic steps the process performed in this study can be explained: (1) Obtaining the Pareto optimal solution sets using NDS-TLBO approach in MATLAB; (2) Employ the steps Entropy methods to determine the weights of the main objective criteria; (3) Employ the steps of TOPSIS and SAW methods to the ranking of the Pareto optimal solutions and (4) comparing the findings with each other (see Figure 1). A brief explanation of TOPSIS, and SAW methods are given in the following subsections.

Alternative weights creation options are taken as in Table 1 in order to further verify the effect of weights on the MCDM approaches. O1 Index indicates that 0.999 is the weight for the time criteria and 0.001 is the weight for the cost criteria which is obtained using entropy weight approach. To put it simply, these entropy weight values meaning that the time is more significant than the cost to the contractors. Similarly, rest of the indices are given in the same way by the decision maker's preference to observe the effect of the weights on criteria.

Table 1. Alternative weights created by the decision maker's preference for the MCDM approaches.

\begin{tabular}{lll}
\hline Indices & Weights for time - criteria & Weights for cost - criteria \\
\hline O1 & 0.999 & 0.001 \\
O2 & 0.001 & 0.999 \\
O3 & 0.5 & 0.5 \\
\hline
\end{tabular}

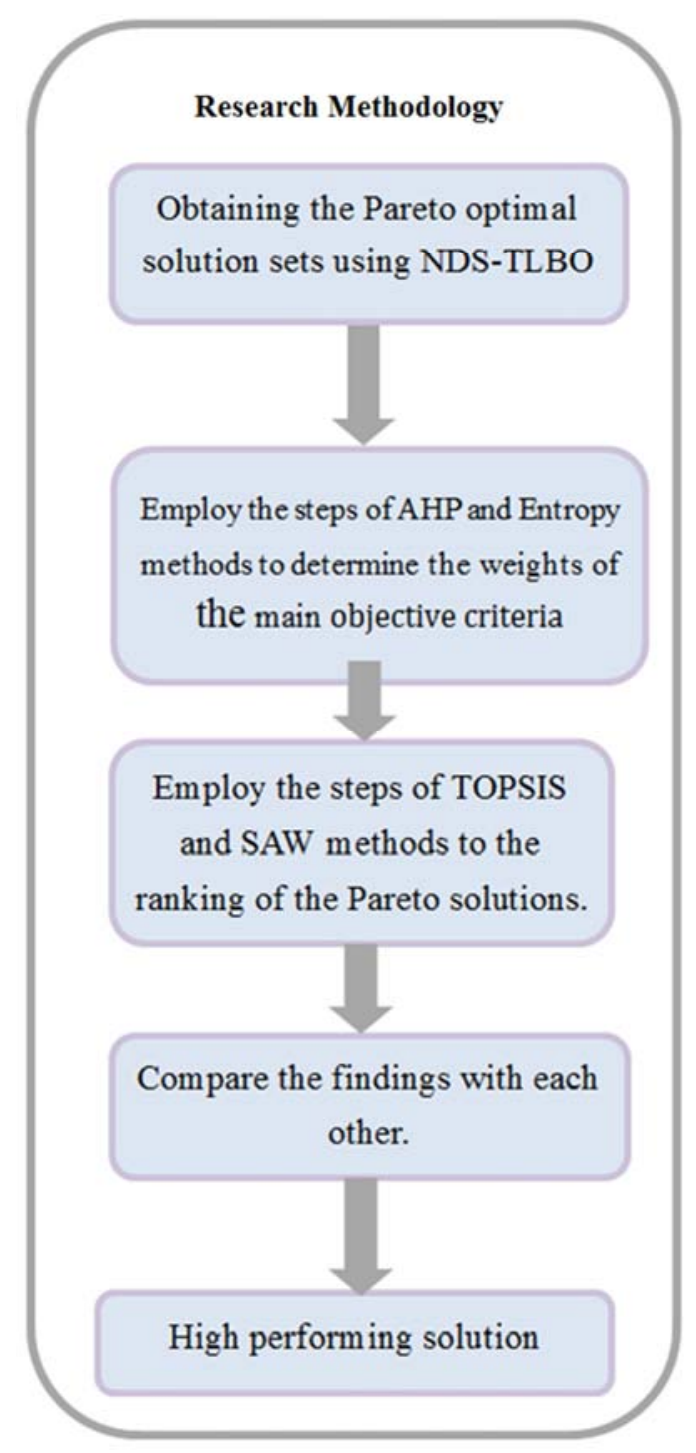

Figure 1. The basic steps of the Pareto-front selection process.

\subsection{Shannon's Entropy Method}

In the AHP method and other similar evaluation methods, determination of criteria weights is critical. One issue about the weight assignment is that the calculation contains only the information of the individual indicator and thus ignores the relationship among other objectives. The entropy method has been proposed to solve such problems because the entropy weight objectively reflects the original data in a more comprehensive way. The steps of the process are given below:

As mentioned earlier, Shannon's entropy is a common method in achieving the weights for a MCDM problem particularly when attaining a suitable weight based on the preferences and DM experiments are found to be difficult. The original procedure of Shannon's entropy can be expressed in a series of steps:

S1: Normalize the decision matrix.

$$
\text { Set } \mathrm{pij}=\frac{X i j}{\sum_{j=1}^{m} X i j}, \mathrm{j}=1 \ldots \mathrm{m}, \mathrm{i}=1 \ldots \mathrm{n}
$$

It is better to eliminate anomalies with various 
measurement units and scales to normalize the raw data. This process transforms different scales and units among various criteria into common measurable units to allow for comparisons of different criteria.

$\mathrm{S} 2$ : Compute entropy hi as $\mathrm{hi}=-\mathrm{h} 0 \sum_{j=1}^{m} P i j \cdot \ln P i j, \mathrm{i}=1 \ldots \mathrm{n}$, where $\mathrm{h} 0$ is the entropy constant and is equal to ( $\ln \mathrm{m})-1$, and $\mathrm{p}_{\mathrm{ij}}$. in $\mathrm{p}_{\mathrm{ij}}$ is defined as 0 if $\mathrm{p}_{\mathrm{ij}}=0$.

S3: Set di $=1-h i, i=1 \ldots n$ as the degree of diversification.

S4: Set wi $=\frac{d i}{\sum_{s=1}^{n} d s}, \mathrm{i}=1 \ldots \mathrm{n}$ as the degree of importance of attribute i.

This approach is frequently being used in widespread in order to obtain the weights objectively.

\subsection{TOPSIS (Technique for Order Preference by Similarity to Ideal Solution)}

TOPSIS is a very common technique in the field of multi-criteria decision making which was first proposed by Hwang and Yoon [1]. The TOPSIS method is one of the multi- criteria decision-making methods. The TOPSIS method can be applied directly to the data without qualitative conversion. The TOPSIS method involves the ranking of the other projects based on the most ideal project for each criterion in the set of options to be evaluated. The method is based on the assumption that the alternative to be selected should be the shortest distance from the positive ideal solution and the farthest distance from the negative ideal solution. With this method, alternatives are compared according to certain criteria and by evaluating the distances between the maximum and minimum values that the criteria can take to the ideal solution and the non-ideal solution. Then the most similar alternative is chosen. The TOPSIS technique attempts to rank the alternatives based on two parameters; (a) minimum distance from the positive ideal solution; (b) farthest distance from the negative ideal solution. The TOPSIS technique has been widely used in many fields, e.g., management of supply chain industrial robotic system selection, the optimal green supplier selection procedure. In this study, the TOPSIS technique is integrated to the body of TLBO algorithm in order to rank the Pareto-optimal solutions obtained from multiobjective optimization techniques. The TOPSIS method follows the following steps.

1. Step: Vector normalization. The matrix is normalized by taking the square root of the sum of the points or properties of the criteria in the decision matrix. This process is done with the following formula.

$$
\mathrm{r}_{i j}=\frac{x_{i j}}{\sqrt{\sum_{i=1}^{m} X_{i j}^{2}}} \mathrm{i}=1,2,3 \ldots \ldots . \mathrm{m} \text { (projects), } \mathrm{j}=1,2,3 \ldots n
$$

2. Step: Weighting normalized values. The elements of the normalized decision matrix are weighted according to the importance given to the criteria (creation of a weighted normalized decision matrix). The normalized version of the 10-point scale is used for weighting. This is done as follows. $\mathrm{Vij}=\mathrm{wj}$ * rij where wj; is the weight of the jth criterion.

3. Step: Finding the positive and negative ideal solutions A $+(\mathrm{A} *)$ and $\mathrm{A}$-ideal points are defined: Here the maximum and minimum values are determined in each column in the weighted matrix.

The ideal solution consists of the best performance values of the weighted normalized decision matrix; the negative ideal solution consists of the worst values.

$\mathrm{A}+$ (ideal solution) and A- (negative ideal solution) are calculated by the following equations.

$\mathrm{A}+=\{\mathrm{v} 1+, \mathrm{v} 2+\ldots \mathrm{vn}+\}$ (maximum values)

$\mathrm{A}-=\{\mathrm{v} 1-, \mathrm{v} 2-\ldots \mathrm{vn}-\}$ (minimum values)

$$
\begin{aligned}
& A+=\{(\max v i j / j \in J),(\max v i j / j \in J+) \\
& A-=\{(\max v i j / j \in J),(\max v i j / j \in J+)
\end{aligned}
$$

4. Step: Calculation of the Euclidean distance ( $\mathrm{Si}+, \mathrm{Si}-)$ of the options to the ideal solutions The distance of the $\mathrm{J}$ alternative from the ideal solution is the ideal separation $(\mathrm{Si}+)$ and the distance from the negative ideal solution to the negative ideal separation ( $\mathrm{Si}-)$ is calculated using the following formulas.

$$
\begin{gathered}
S_{i}^{+}=\sqrt{\sum_{j=1}^{n}\left(v_{i j}-v_{J}^{+}\right)^{2}} \\
S_{i}^{-}=\sqrt{\sum_{j=1}^{n}\left(v_{i j}-v_{J}^{-}\right)^{2}}
\end{gathered}
$$

5. Step: Calculation of the similarities of the options to the positive ideal solution $(\mathrm{Ci}+)$ The $\mathrm{Ci}+$ (Proximity to Ideal Solution) is calculated by the following formula.

$$
\mathrm{C}_{\mathrm{i}}^{*}=\frac{\mathrm{S}_{\mathrm{i}}^{-}}{\mathrm{S}_{\mathrm{i}}^{-}+\mathrm{S}_{\mathrm{i}}^{+}}
$$

\subsection{Simple Additive Weighting (SAW)}

It is believed that one of the largely preferred MCDM methods is SAW method. It is based on the weighted average evaluation of the attributes. In the SAW method, each one of the attributes is given a certain weight and each alternative is specified with respect to the corresponding attribute. By multiplying the scaled value, calculation of an evaluation score is carried out for each alternative. SAW involves the following steps. Obtain the decision matrix.

Obtain the normalized decision

$$
r_{i j}=\left\{\begin{array}{ccc}
\frac{x_{i j}}{\max x_{i j}}, & i=1, \ldots \ldots . m ; & j=1 \ldots . . n \\
\frac{\min x_{i j}}{x_{i j}}, & i=1, \ldots \ldots . m ; & j=1 \ldots . . n
\end{array}\right\}
$$

Where $\mathrm{xij} / \mathrm{max} \mathrm{xij}$ is used for positive criteria and min $\mathrm{xij} / \mathrm{xij}$ is used for negative criteria. Here, $\mathrm{xij}$ is the criterion value, max $x i j$ is the maximum value for each positive 
criterion, min xij is the minimum value for each negative criterion, and rij is the normalized value.

Get the weighted score for each alternative

$$
\mathrm{A}_{j}=\sum_{j=1}^{m} w_{j} r_{i j}, \quad i=1, \ldots \ldots, m .
$$

Here, $x i j$ is the score of alternative $i$ to criteria $j$ and wj is the weight of criteria j. Rank the obtained scores.

\section{Multi-Objective Optimization Techniques}

A time-cost trade-off problem (TCTP) is indeed a multi-objective programming problem that can be unravelled by three distinct methods. In the first method, one seeks the satisfactory solution from the nod-dominated solutions based on the experiences and knowledge of decision makers, whereas the determination of the non-inferior solutions is a bit more sophisticated and complicated. The second converts the multi-objective problem to a single-objective problem, and then utilizing a single-objective optimization approach to find the satisfactory solution which is known as weighted method. The final approach utilizes a multi-objective optimization approach to find the satisfactory solution. The method utilized in this paper belongs to the first category, which provides a satisfactory solution, and also determines Pareto-front solution that is beneficial for the further decision making process.

\subsection{Time-Cost Trade-Off Optimization}

The main goal of a discrete TCT optimization problem is to determine a set of time-cost alternatives which provide an optimal balance between the time and cost for project scheduling under the specific conditions. The TCT analysis is implemented to meet the project deadline for a project with a fixed deadline or for a project which is running behind schedule. As mentioned above, TCTP mainly concentrates on selecting appropriate options for every activity to obtain the objective of time and cost of a project. The objective of time of a project can be calculated according to Equations (11) - (14).

$$
\begin{gathered}
E S_{0}=0 \text { (the subscript } 0 \text { represent zero) } \\
E S_{j}=\max _{i \in p_{j}}\left\{E F_{i}\right\} \quad j=i, \ldots, n+1 \\
E F_{i}=E S_{i}+t_{i}^{(k)} x_{i}^{(k)} \quad i=0, \cdots, n+1 \\
T=\sum_{i}^{k} t_{i}^{k} x_{i}^{k}
\end{gathered}
$$

Where, $\mathrm{T}$ is the total time duration of the project and maximization of which is one of the objectives of TCTP. It represents the complete time of critical activities placed on the critical path of the project activity network. ESj and EFj are earliest start time and earliest finish time, respectively; $\mathrm{pj}$ is immediate predecessor of activity $\mathrm{j}$; $\mathrm{ti}(\mathrm{k})$ is duration of activity $\mathrm{i}$ for the kth option; and $\mathrm{xi}(\mathrm{k})$ is index variable of activity $\mathrm{i}$. If $x i(\mathrm{k})=1$, then activity i performs the kth option, while xi $(\mathrm{k})=0$ means not. The sum of index variables of all options should be equal to 1 . Activity $0(n+1)$ is the only dummy activity.

The total cost of a project composes of direct cost and indirect cost. Sum of direct cost of all activities within a project network gives the direct cost. Besides, indirect cost depends on the project duration. Thus, indirect cost increases as the finishing date of a project is getting longer. Afterwards, Equations. (15) - (17) are applied to calculate the total cost of a project.

$$
\begin{gathered}
D C=\sum_{i}^{k} D C_{i}^{k} x_{i}^{k}+t_{i} \times i c_{i}^{k} \\
\mathrm{IC}=\mathrm{T} \times \mathrm{ICR} \\
\mathrm{C}=\mathrm{DC}+\mathrm{IC}
\end{gathered}
$$

Where DC and IC, respectively, are the total direct and indirect costs of a project; $\mathrm{C}$ is the total cost of a project; dci $(\mathrm{k})$ xi (k) shows the direct cost of activity i under the kth option; and ICR is the indirect cost rate of a project.

\subsection{Non-dominating Sorting Approach}

In this study, to overcome the deficiency of modified adaptive weight approach (MAWA), an effective and more promising non-dominating sorting (NDS) concept is employed to obtain the Pareto optimal solutions of time cost trade-off problems. In contrast to MAWA approach, there is no unique solution provided by NDS approach, but Pareto front solutions are produced and selected by comparing two solutions to each other. This NDS approach seeks the satisfactory solution from the non-dominated solutions depending on the experience and knowledge of decision-makers. The employed multi-objective TLBO algorithm can find out the Pareto front solution which provides flexibility to planners and decision makers in making efficient time-cost decisions. The concept of the Pareto front solution is the commonly accepted tool for comparing two solutions in multi-objective optimization that have no unified criterion with respect to optima. In addition to this, to develop a flexible time-cost trade-off (TCT) model, critical path method (CPM) scheduling in MATLAB to be used for applying multi-objective TLBO optimization engine and then integrating with the MCDM approaches to rank the obtained solutions. The results reveal that NDS-TLBO is more effective as compared to other state-of-the-art algorithms. The flowchart of the process is given in Figure 2. 


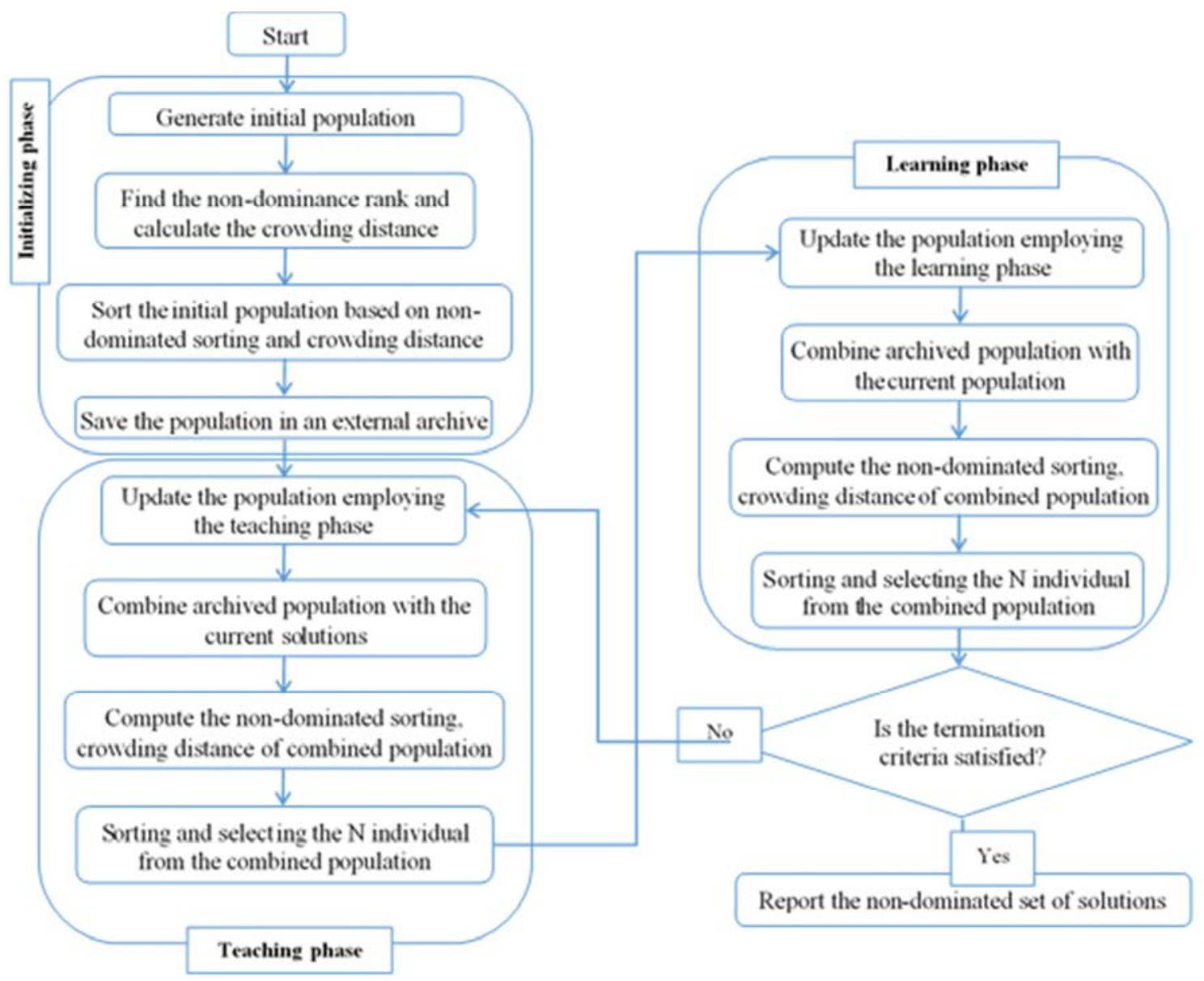

Figure 2. Flowchart of the NDS-TLBO algorithm for TCTP.

\section{Description of the Benchmark Case Problem}

\subsection{Small-Scale Test Problem}

To verify and demonstrate the efficiency of the proposed model to integrate the MCDM methods, namely, Entropy, SAW and TOPSIS, into TCTPs, a small-scale project activity network consisting of 18 activities, first proposed by [18], was adapted. Furthermore, medium scale 63 activities Benchmark Case problems taken from the technical literature is investigated. The utilized algorithm was executed in MATLAB environment and implemented on a personal computer having Intel (R) Core (TM) i3 CPU $2.40 \mathrm{GHz}$ and 3GB RAM. The activity on the node network diagram of the case study is illustrated in Figure 3. The corresponding time and cost for each mode of activities are listed in Table 2.

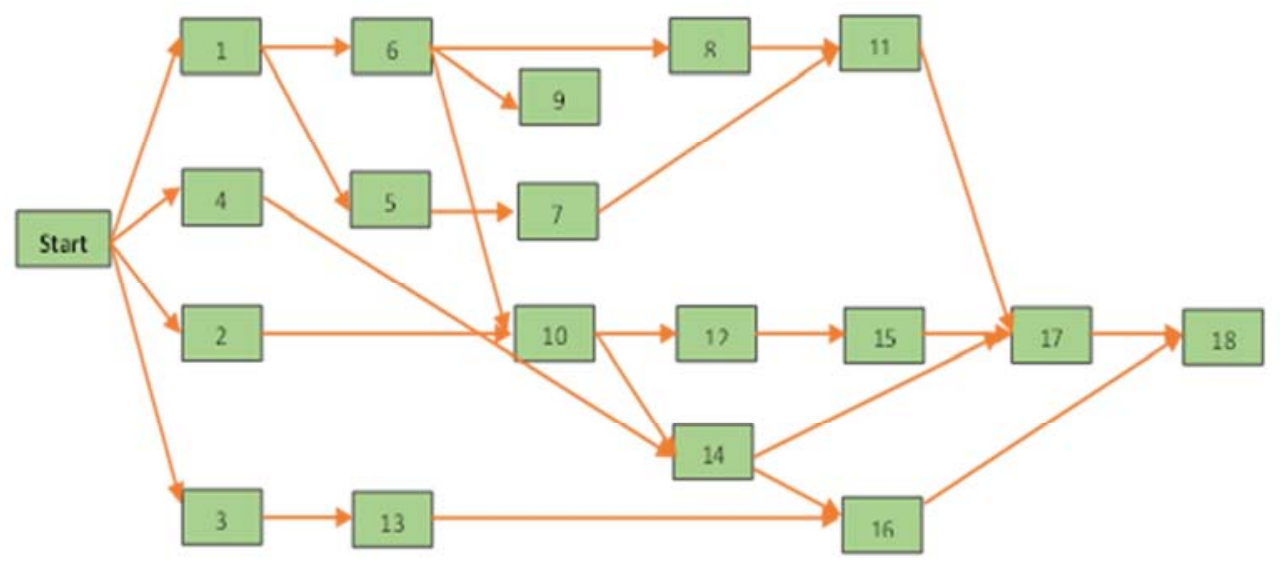

Figure 3. Network configuration for the model project of 18 activities. 
Table 2. Options for 18 activities project with five modes.

\begin{tabular}{|c|c|c|c|c|c|c|c|c|c|c|c|}
\hline \multicolumn{2}{|l|}{ Activities } & \multicolumn{10}{|c|}{5 Methods of Construction - Normal to Crash } \\
\hline \multirow{2}{*}{$\begin{array}{l}\text { Activity } \\
\text { Number }\end{array}$} & \multirow{2}{*}{$\begin{array}{l}\text { Precedent } \\
\text { Activity }\end{array}$} & \multicolumn{2}{|c|}{ Option / Mode1 } & \multicolumn{2}{|c|}{ Option / Mode 2} & \multicolumn{2}{|c|}{ Option / Mode 3} & \multicolumn{2}{|c|}{ Option/Mode4 } & \multicolumn{2}{|c|}{ Option/Mode5 } \\
\hline & & $\begin{array}{l}\text { Dur } \\
\text { (day) }\end{array}$ & $\begin{array}{l}\text { Direct } \\
\text { Cost }\end{array}$ & $\begin{array}{l}\text { Dur } \\
\text { (day) }\end{array}$ & $\begin{array}{l}\text { Direct } \\
\text { Cost }\end{array}$ & $\begin{array}{l}\text { Dur } \\
\text { (day) }\end{array}$ & $\begin{array}{l}\text { Direct } \\
\text { Cost }\end{array}$ & $\begin{array}{l}\text { Dur } \\
\text { (day) }\end{array}$ & Direct Cost & $\begin{array}{l}\text { Dur } \\
\text { (day) }\end{array}$ & DirectCost \\
\hline 1 & - & 14 & 2400 & 15 & 2150 & 16 & 2400 & 21 & 1500 & 24 & 1200 \\
\hline 2 & - & 15 & 300 & 18 & 2400 & 20 & 1900 & 23 & 1500 & 25 & 1000 \\
\hline 3 & - & 15 & 4500 & 22 & 4000 & 33 & 1800 & & & & \\
\hline 4 & - & 12 & 45000 & 16 & 35000 & 20 & 3200 & & & & \\
\hline 5 & 1 & 22 & 20000 & 24 & 17500 & 28 & 30000 & 30 & 10000 & & \\
\hline 6 & 1 & 14 & 40000 & 18 & 32000 & 24 & 15000 & & & & \\
\hline 7 & 5 & 9 & 30000 & 15 & 24000 & 18 & 18000 & & & & \\
\hline 8 & 6 & 14 & 220 & 15 & 21 & 16 & 22000 & 21 & & 24 & \\
\hline 9 & 6 & 15 & 300 & 18 & 240 & 20 & 200 & 23 & 208 & 25 & 120 \\
\hline 10 & 2,6 & 15 & 450 & 22 & 400 & 33 & 180 & & 150 & & 100 \\
\hline 11 & 7,8 & 12 & 450 & 16 & 350 & 20 & 320 & & & & \\
\hline 12 & $5,9,10$ & 22 & 2000 & 24 & 1750 & 28 & 1500 & 30 & & & \\
\hline 13 & 3 & 14 & 4000 & 18 & 3200 & 24 & 1800 & & & & \\
\hline 14 & 4,10 & 9 & 3000 & 15 & 2400 & 18 & 2200 & & & & \\
\hline 15 & 12 & 12 & 4500 & 16 & 3500 & & & & & & \\
\hline 16 & 13,14 & 20 & 3000 & 22 & 2000 & 24 & 1750 & 28 & 1500 & 30 & 1000 \\
\hline 17 & $11,14,15$ & 14 & 4000 & 18 & 3200 & 24 & 1800 & & & & 1200 \\
\hline 18 & 16,17 & 9 & 3000 & 15 & 2400 & 18 & 2200 & & & & 1000 \\
\hline
\end{tabular}

The obtained ranking value using TOPSIS as well as SAW approaches adapting the entropy weight values is tabulated in table 3. It simply means that the time is more valuable than the cost of the project. In this case, contractor or any other decision makers are giving more and more importance to the timespan of the project. And also, Pareto optimal solutions of 18 activities problem obtained by NDS-TLBO algorithm is graphically presented in Figure 4.

Table 3. Comparison of Pareto fronts located for 18-activity problem using NDS-TLBO.

\begin{tabular}{|c|c|c|c|c|c|c|c|c|}
\hline Dur. (days) & Zhang [13] & NDS-TLBO (This paper) & $\mathbf{S}_{i}^{+}$ & $\mathbf{S}_{i}^{-}$ & $\mathbf{C}_{i}$ & TOPSIS Ranking & Sum of the Row & SAW Ranking \\
\hline 100 & 287720 & 283320 & 10.103 & 152.315 & 0.938 & 2 & 0.9091818 & 4 \\
\hline 101 & 284020 & 279820 & 9.801 & 149.268 & 0.938 & 3 & 0.9182513 & 3 \\
\hline 104 & 280020 & 276320 & 9.376 & 146.984 & 0.940 & 1 & 0.9454844 & 2 \\
\hline 110 & 273720 & 271270 & 12.032 & 144.711 & 0.923 & 4 & 0.9999575 & 1 \\
\hline Pop. Size & 50 & 40 & & & & & & \\
\hline Num. of iterations & 500 & 100 & & & & Entropy Weights & $\mathrm{C}_{\mathrm{t}}=0.999 \mathrm{C}_{\mathrm{c}}=0.001$ & \\
\hline NFE & 25000 & 8040 & & & & & & \\
\hline
\end{tabular}

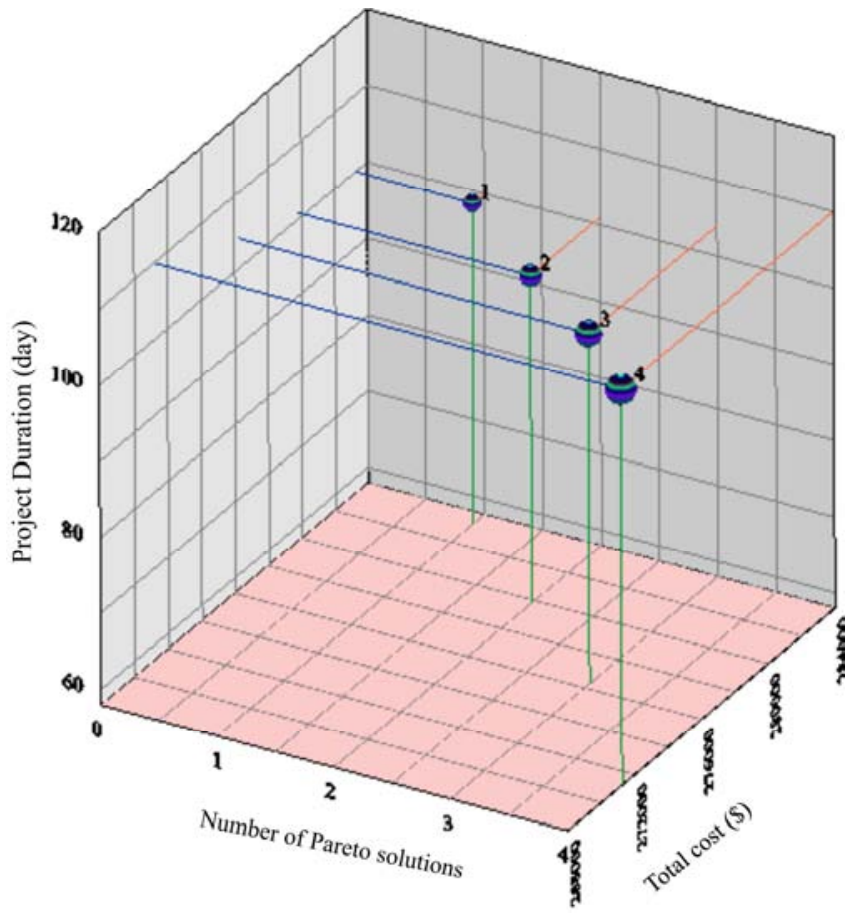

Figure 4. Pareto optimal solutions of 18 activities problem obtained by NDS-TLBO algorithm. 
Table 4. Options selected and solution generated for 18-activity TCTP problem with five modes.

\begin{tabular}{|c|c|c|c|c|c|c|c|c|c|c|c|c|c|c|c|c|c|c|c|c|}
\hline \multirow{2}{*}{$\begin{array}{l}\text { PF } \\
\text { Sol }\end{array}$} & \multirow{2}{*}{$\begin{array}{l}\text { Proj. Time } \\
\text { (day) }\end{array}$} & \multirow{2}{*}{$\begin{array}{l}\text { Project } \\
\text { Cost (\$) }\end{array}$} & \multicolumn{18}{|c|}{ Selected duration of the corresponding activity (days) } \\
\hline & & & 1 & 2 & 3 & 4 & 5 & 6 & 7 & 8 & 9 & 10 & 11 & 12 & 13 & 14 & 15 & 16 & 17 & 18 \\
\hline 1 & 100 & 283320 & 14 & 25 & 33 & 20 & 28 & 14 & 18 & 24 & 15 & 15 & 16 & 22 & 24 & 18 & 12 & 30 & 14 & 9 \\
\hline 2 & 101 & 279820 & 14 & 25 & 33 & 20 & 30 & 14 & 18 & 24 & 15 & 15 & 16 & 22 & 24 & 18 & 12 & 30 & 14 & 9 \\
\hline 3 & 104 & 276320 & 14 & 25 & 33 & 20 & 30 & 18 & 18 & 24 & 15 & 15 & 16 & 22 & 24 & 18 & 12 & 30 & 14 & 9 \\
\hline 4 & 110 & 271270 & 14 & 25 & 33 & 20 & 30 & 24 & 18 & 24 & 15 & 15 & 20 & 22 & 24 & 18 & 12 & 30 & 14 & 9 \\
\hline
\end{tabular}

Table 4 shows the options selected and solution generated for 18-activity TCTP problem. And obtained rankings using TOPSIS as well as SAW approaches considering the optional weights are given in Tables 5 and 6 . It simply means in both the cases the cost is more valuable than the time of the project. Therefore, contractors or any other decision makers are paying more attention to the cost of the project.

Table 5. Result matrix of TOPSIS method using different weights.

\begin{tabular}{|c|c|c|c|c|c|c|c|c|c|c|}
\hline \multirow{3}{*}{$\begin{array}{l}\text { Sr. } \\
\text { No }\end{array}$} & \multirow{2}{*}{\multicolumn{2}{|c|}{ NDS-TLBO }} & \multicolumn{3}{|c|}{ Different weight preferences } & \multirow{3}{*}{$\begin{array}{l}\text { TOPSIS } \\
\text { Ranking }\end{array}$} & \multicolumn{3}{|c|}{ Equal weight } & \multirow{3}{*}{$\begin{array}{l}\text { TOPSIS } \\
\text { Ranking }\end{array}$} \\
\hline & & & \multirow{2}{*}{$\begin{array}{l}C_{\mathrm{t}}=0.001 \\
\mathrm{~S}_{i}^{+}\end{array}$} & \multicolumn{2}{|l|}{$C_{\mathrm{c}}=0.999$} & & \multirow{2}{*}{$\begin{array}{l}C_{\mathrm{t}}=0.5 \\
\mathrm{~S}_{i}^{+}\end{array}$} & \multicolumn{2}{|l|}{$C_{\mathrm{c}}=0.5$} & \\
\hline & Dur & Cost & & $\mathbf{S}_{i}^{-}$ & $\mathbf{C}_{i}$ & & & $\mathbf{S}_{i}^{-}$ & $\mathbf{C}_{i}$ & \\
\hline 1 & 100 & 283320 & 0.010 & 144372.8 & 0.999 & 1 & 5.057 & 72258.70 & 0.999 & 1 \\
\hline 2 & 101 & 279820 & 3544.99 & 140827.8 & 0.975 & 3 & 1774.277 & 70484.42 & 0.975 & 2 \\
\hline 3 & 104 & 276320 & 7045.92 & 137326.9 & 0.951 & 2 & 3526.490 & 68732.21 & 0.951 & 4 \\
\hline 4 & 110 & 271270 & 12019.60 & 132353.2 & 0.917 & 4 & 6015.819 & 66242.88 & 0.917 & 3 \\
\hline
\end{tabular}

Table 6. Result matrix of SAW method using different weights.

\begin{tabular}{|c|c|c|c|c|c|}
\hline \multicolumn{2}{|c|}{ NDS-TLBO } & Sum of the Row & SAW Ranking & Sum of the Row & SAW Ranking \\
\hline \multirow{2}{*}{ Dur } & \multirow{2}{*}{ Cost } & \multicolumn{2}{|c|}{ Different weight preferences } & \multicolumn{2}{|l|}{ Equal weight } \\
\hline & & $C_{\mathrm{t}}=0.001$ & $C_{\mathrm{c}}=0.999$ & $C_{\mathrm{t}}=0.5$ & $C_{\mathrm{c}}=0.5$ \\
\hline 100 & 283320 & 0.9999091 & 1 & 0.9545455 & 3 \\
\hline 101 & 279820 & 0.9875770 & 2 & 0.9529141 & 4 \\
\hline 104 & 276320 & 0.9752631 & 3 & 0.9603738 & 2 \\
\hline 110 & 271270 & 0.9575111 & 4 & 0.9787343 & 1 \\
\hline
\end{tabular}

\subsection{Medium-Scale Test Problem}

A medium-scale project with 63 activities taken from the literature is examined as a second test project to exhibit the performance of the proposed NDS-TLBO. Subsequently, the obtained Pareto-optimal solutions are ranked to have a clear guidance for the contractors. The activity-on-node diagram for the project is presented in Figure. 5, and the time-cost optional modes are given in Table 7.

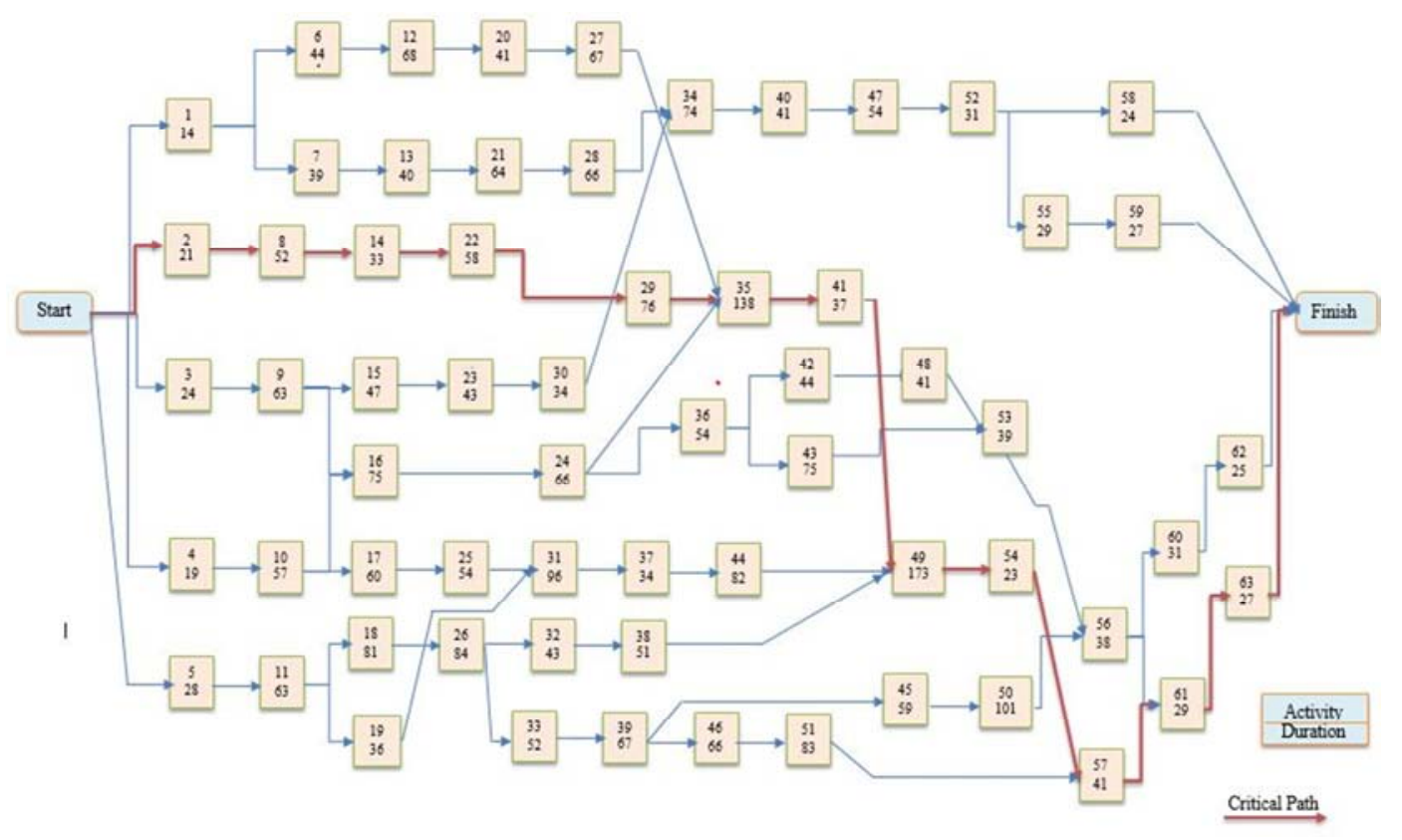

Figure 5. Network representation of the 63 activities project. 
Table 7. Data for the project with 63 activities.

\begin{tabular}{|c|c|c|c|c|c|c|c|c|c|c|c|}
\hline \multirow{2}{*}{$\begin{array}{l}\text { Activity } \\
\text { num. }\end{array}$} & \multirow{2}{*}{$\begin{array}{l}\text { Precedent } \\
\text { Activity }\end{array}$} & \multicolumn{2}{|c|}{ Option / Mode 1} & \multicolumn{2}{|c|}{ Option / Mode 2} & \multicolumn{2}{|c|}{ Option / Mode 3} & \multicolumn{2}{|c|}{ Option / Mode 4} & \multicolumn{2}{|c|}{ Option / Mode 5} \\
\hline & & Dur (days) & Cost (\$) & Dur (days) & Cost (\$) & Dur (days) & Cost (\$) & Dur (days) & Cost (\$) & Dur (days) & Cost (\$) \\
\hline 1 & - & 14 & 3700 & 12 & 4250 & 10 & 5400 & 9 & 6250 & & \\
\hline 2 & - & 21 & 11250 & 18 & 14800 & 17 & 16200 & 15 & 19650 & & \\
\hline 3 & - & 24 & 22450 & 22 & 24900 & 19 & 27950 & 17 & 31650 & & \\
\hline 4 & - & 19 & 17800 & 17 & 19400 & 15 & 21600 & - & & & \\
\hline 5 & - & 28 & 31180 & 26 & 34200 & 23 & 38250 & 21 & 41400 & & \\
\hline 6 & 1 & 44 & 54260 & 42 & 58450 & 38 & 63225 & 35 & 68150 & & \\
\hline 7 & 1 & 39 & 47600 & 36 & 50750 & 33 & 54800 & 30 & 59750 & & \\
\hline 8 & 2 & 52 & 62140 & 47 & 69700 & 44 & 72600 & 39 & 81750 & & \\
\hline 9 & 3 & 63 & 72750 & 59 & 79450 & 55 & 86250 & 51 & 91500 & 49 & 99500 \\
\hline 10 & 4 & 57 & 66500 & 53 & 70250 & 50 & 75800 & 46 & 80750 & 41 & 86450 \\
\hline 11 & 5 & 63 & 83100 & 59 & 89450 & 55 & 97800 & 50 & 104250 & 45 & 112400 \\
\hline 12 & 6 & 68 & 75500 & 62 & 82000 & 58 & 87500 & 53 & 91800 & 49 & 96550 \\
\hline 13 & 7 & 40 & 34250 & 37 & 38500 & 33 & 43950 & 31 & 48750 & & \\
\hline 14 & 8 & 33 & 52750 & 30 & 58450 & 27 & 63400 & 25 & 66250 & & \\
\hline 15 & 9 & 47 & 38140 & 40 & 41500 & 35 & 47650 & 32 & 54100 & & \\
\hline 16 & 9,10 & 75 & 94600 & 70 & 101250 & 66 & 112750 & 61 & 124500 & 57 & 132850 \\
\hline 17 & 10 & 60 & 78450 & 55 & 84500 & 49 & 91250 & 47 & 94640 & & \\
\hline 18 & 10,11 & 81 & 127150 & 73 & 143250 & 66 & 154600 & 47 & 161900 & & \\
\hline 19 & 11 & 36 & 82500 & 34 & 94800 & 30 & 101700 & - & & & \\
\hline 20 & 12 & 41 & 48350 & 37 & 53250 & 34 & 59450 & 32 & 66800 & & \\
\hline 21 & 13 & 64 & 85250 & 60 & 92600 & 57 & 99800 & 53 & 107500 & 49 & 113750 \\
\hline 22 & 14 & 58 & 74250 & 53 & 79100 & 50 & 86700 & 47 & 91500 & 42 & 97400 \\
\hline 23 & 15 & 43 & 66450 & 41 & 69800 & 37 & 75800 & 33 & 81400 & 30 & 88450 \\
\hline 24 & 16 & 66 & 72500 & 62 & 78500 & 58 & 83700 & 53 & 89350 & 49 & 96400 \\
\hline 25 & 17 & 54 & 66650 & 50 & 70100 & 47 & 74800 & 43 & 79500 & 40 & 86800 \\
\hline 26 & 18 & 84 & 93500 & 79 & 102500 & 73 & 111250 & 68 & 119750 & 62 & 128500 \\
\hline 27 & 20 & 67 & 78500 & 60 & 86450 & 57 & 89100 & 56 & 91500 & 53 & 94750 \\
\hline 28 & 21 & 66 & 85000 & 63 & 89750 & 60 & 92500 & 58 & 96800 & 54 & 100500 \\
\hline 29 & 22 & 76 & 92700 & 71 & 98500 & 67 & 104600 & 64 & 109900 & 60 & 115600 \\
\hline 30 & 23 & 34 & 27500 & 32 & 29800 & 29 & 31750 & 27 & 33800 & 26 & 36200 \\
\hline 31 & 19,25 & 96 & 145000 & 89 & 154800 & 83 & 168650 & 77 & 179500 & 72 & 189100 \\
\hline 32 & 26 & 43 & 43150 & 40 & 48300 & 37 & 51450 & 35 & 54600 & 33 & 61450 \\
\hline 33 & 26 & 52 & 61250 & 49 & 64350 & 44 & 68750 & 41 & 74500 & 38 & 79500 \\
\hline 34 & 28,30 & 74 & 89250 & 71 & 93800 & 66 & 99750 & 62 & 105100 & 57 & 114250 \\
\hline 35 & $24,27,29$ & 138 & 183000 & 126 & 201500 & 115 & 238000 & 103 & 283750 & 98 & 297500 \\
\hline 36 & 24 & 54 & 47500 & 49 & 50750 & 42 & 56800 & 38 & 62750 & 33 & 68250 \\
\hline 37 & 31 & 34 & 22500 & 32 & 24100 & 29 & 26750 & 27 & 29800 & 24 & 31600 \\
\hline 38 & 32 & 51 & 61250 & 47 & 65800 & 44 & 71250 & 41 & 76500 & 38 & 80400 \\
\hline 39 & 33 & 67 & 81150 & 61 & 87600 & 57 & 92100 & 52 & 97450 & 49 & 102800 \\
\hline 40 & 34 & 41 & 45250 & 39 & 48400 & 36 & 51200 & 33 & 54700 & 31 & 58200 \\
\hline 41 & 35 & 37 & 17500 & 31 & 21200 & 27 & 26850 & 23 & 32300 & & \\
\hline 42 & 36 & 44 & 36400 & 41 & 39750 & 38 & 42800 & 32 & 48300 & 30 & 50250 \\
\hline 43 & 36 & 75 & 66800 & 69 & 71200 & 63 & 76400 & 59 & 81300 & 54 & 86200 \\
\hline 44 & 37 & 82 & 102750 & 76 & 109500 & 70 & 127000 & 66 & 136800 & 63 & 146000 \\
\hline 45 & 39 & 59 & 847500 & 55 & 91400 & 51 & 101300 & 47 & 126500 & 43 & 142750 \\
\hline 46 & 39 & 66 & 94250 & 63 & 99500 & 59 & 108250 & 55 & 118500 & 50 & 136000 \\
\hline 47 & 40 & 54 & 73500 & 51 & 78500 & 47 & 83600 & 44 & 88700 & 41 & 93400 \\
\hline 48 & 42 & 41 & 36750 & 39 & 39800 & 37 & 43800 & 34 & 48500 & 31 & 53950 \\
\hline 49 & $38,41,44$ & 173 & 267500 & 159 & 289700 & 147 & 312000 & 138 & 352500 & 121 & 397750 \\
\hline 50 & 45 & 101 & 47800 & 74 & 61300 & 63 & 76800 & 49 & 91500 & & \\
\hline 51 & 46 & 83 & 84600 & 77 & 93650 & 72 & 98500 & 65 & 104600 & 61 & 113200 \\
\hline 52 & 47 & 31 & 23150 & 28 & 27600 & 26 & 29800 & 24 & 32750 & 21 & 35200 \\
\hline 53 & 43,48 & 39 & 31500 & 36 & 34250 & 33 & 37800 & 29 & 41250 & 26 & 44600 \\
\hline 54 & 49 & 23 & 16500 & 22 & 17800 & 21 & 19750 & 20 & 21200 & 18 & 24300 \\
\hline 55 & 52,53 & 29 & 23400 & 27 & 25250 & 26 & 26900 & 24 & 29400 & 22 & 32500 \\
\hline 56 & 50,53 & 38 & 41250 & 35 & 44650 & 33 & 47800 & 31 & 51400 & 29 & 55450 \\
\hline 57 & 51,54 & 41 & 37800 & 38 & 41250 & 35 & 45600 & 32 & 49750 & 30 & 53400 \\
\hline 58 & 52 & 24 & 12500 & 22 & 13600 & 20 & 15250 & 18 & 16800 & 16 & 19450 \\
\hline 59 & 55 & 27 & 34600 & 24 & 37500 & 22 & 41250 & 19 & 46750 & 17 & 50750 \\
\hline 60 & 56 & 31 & 28500 & 29 & 30500 & 27 & 33250 & 25 & 38000 & 21 & 43800 \\
\hline 61 & 56,57 & 29 & 22500 & 27 & 24750 & 25 & 27250 & 22 & 29800 & 20 & 33500 \\
\hline 62 & 60 & 25 & 38750 & 23 & 41200 & 21 & 44750 & 19 & 49800 & 17 & 51100 \\
\hline 63 & 61 & 27 & 9500 & 26 & 9700 & 25 & 10100 & 24 & 10800 & 22 & 12700 \\
\hline
\end{tabular}

The results of the NDS-MTLBO for medium networks indicate that the proposed algorithm normally provides adequate 
optimal and near-optimal solutions for the TCTP. Subsequently, obtained rankings using TOPSIS as well as SAW approaches considering the entropy weights are illustrated in Table 8. To put it simply, rankings obtained using these entropy weights indicating that the time is more significant than the cost to the contractors. Graphical representations of the Pareto front solution of the problem is given in Figure 6.

Table 8. Analysis results of 63b-Activity project for the Case $(I C=\$ 3500)$.

\begin{tabular}{|c|c|c|c|c|c|c|c|c|c|c|}
\hline \multirow{3}{*}{$\begin{array}{l}\text { Pareto } \\
\text { Front }\end{array}$} & \multirow{2}{*}{\multicolumn{2}{|c|}{$\begin{array}{l}\text { Bettemir } \\
\text { NDS-GA }\end{array}$}} & \multirow{2}{*}{\multicolumn{2}{|c|}{$\begin{array}{l}\text { This study } \\
\text { NDS-TLBO }\end{array}$}} & \multicolumn{3}{|c|}{ Obtained Entropy Weights } & \multirow{3}{*}{$\begin{array}{l}\text { TOPSIS } \\
\text { Ranking }\end{array}$} & \multirow{2}{*}{$\begin{array}{l}\text { Sum of the } \\
\text { Row }\end{array}$} & \multirow{2}{*}{$\begin{array}{l}\text { SAW } \\
\text { Ranking }\end{array}$} \\
\hline & & & & & \multirow{2}{*}{$\begin{array}{l}C_{t}=0.999 \\
\mathrm{~S}_{i}^{+}\end{array}$} & \multicolumn{2}{|c|}{$C_{c}=0.001$} & & & \\
\hline & Dur & Cost & Dur & Cost & & $\mathbf{S}_{i}^{-}$ & $\mathbf{C}_{i}$ & & $C_{t}=0.999 C$ & 001 \\
\hline PF1 & 617 & 6462580 & 612 & 6192140 & 5.8655 & 17.041 & 0.74394 & 2 & 0.9919031 & 4 \\
\hline PF2 & 651 & 6411540 & 617 & 6184820 & 9.51946 & 19.637 & 0.67350 & 4 & 0.9999976 & 2 \\
\hline PF3 & 647 & 6442440 & 590 & 6188690 & 18.5612 & 3.4809 & 0.15792 & 10 & 0.9562818 & 7 \\
\hline PF4 & 639 & 6420500 & 588 & 6195910 & 18.5710 & 7.1205 & 0.27715 & 7 & 0.9530447 & 9 \\
\hline PF5 & 648 & 6447900 & 591 & 6191490 & 17.3680 & 5.2324 & 0.23151 & 8 & 0.9579014 & 6 \\
\hline PF6 & 627 & 6433810 & 586 & 6196840 & 19.7309 & 7.6010 & 0.27810 & 6 & 0.9498066 & 10 \\
\hline PF7 & 618 & 6439240 & 592 & 6189140 & 17.3032 & 4.6157 & 0.21058 & 9 & 0.9595201 & 5 \\
\hline PF8 & 623 & 6449790 & 589 & 6199870 & 17.7812 & 9.6987 & 0.35293 & 5 & 0.9546645 & 8 \\
\hline PF9 & 630 & 6443805 & 617 & 6187390 & 7.89552 & 19.704 & 0.71393 & 3 & 0.9999980 & 1 \\
\hline PF10 & 629 & 6450065 & 616 & 6190570 & 5.92089 & 19.332 & 0.76554 & 1 & 0.9983794 & 3 \\
\hline Pop. Size & & - & 180 & & Num. of iterations & - & 450 & & & \\
\hline
\end{tabular}

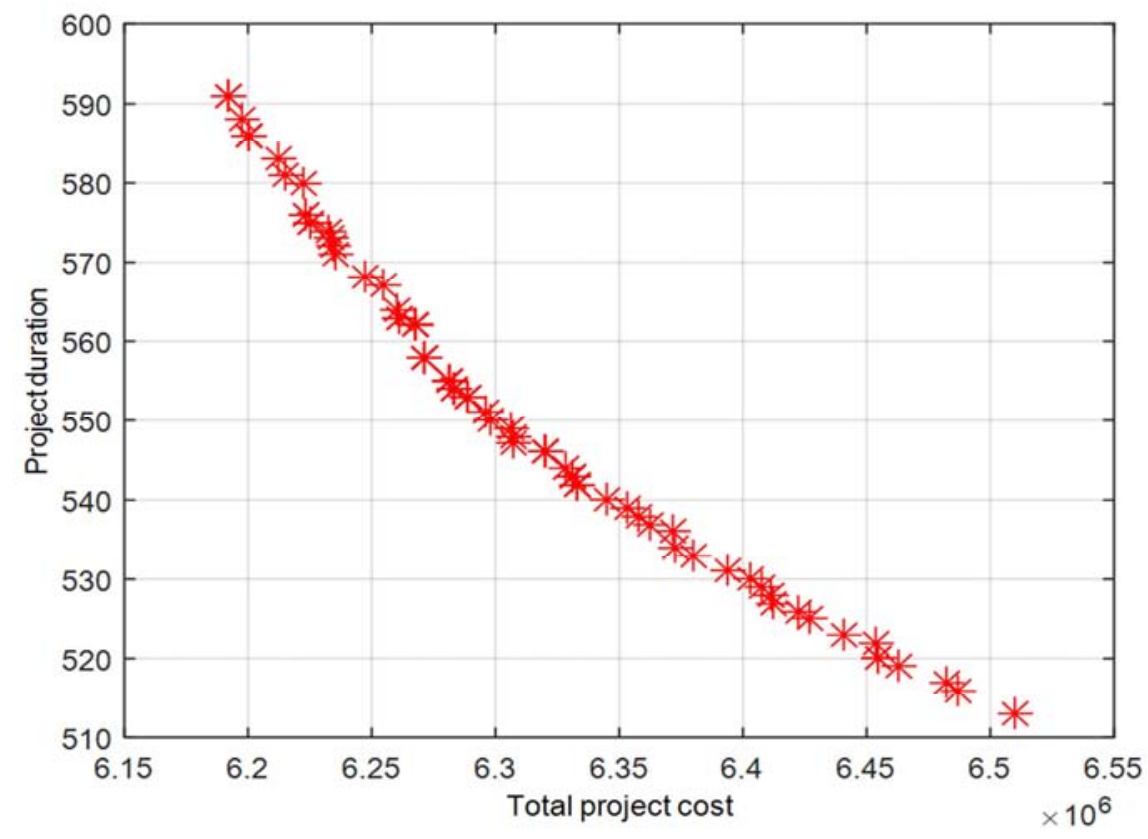

Figure 6. Pareto front solutions of 63 broblem obtained by NDS-TLBO algorithm.

\section{Performans Ranking}

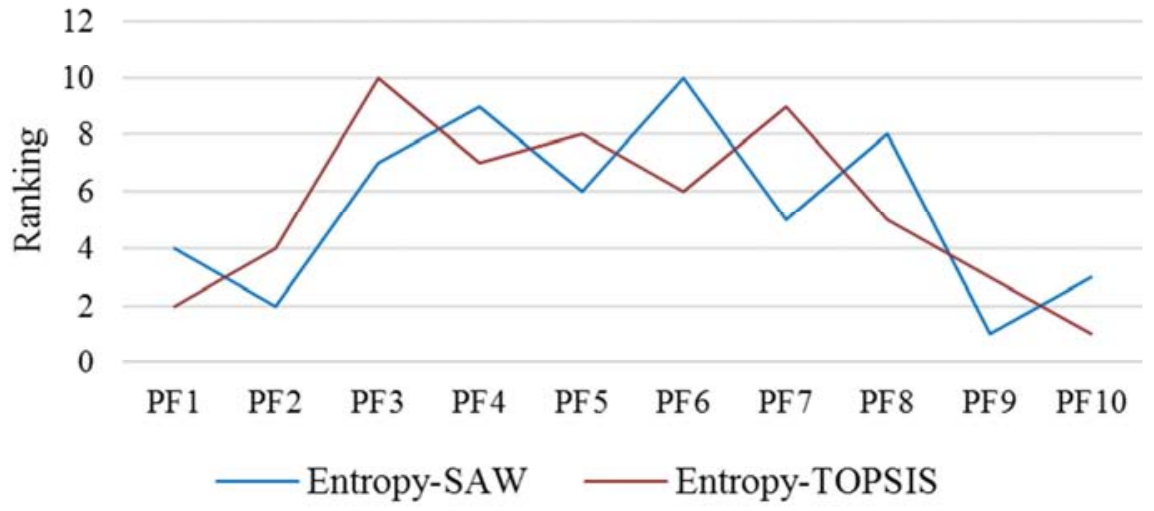

Figure 7. Performance ranking of the Entropy-TOPSIS and Entropy-SAW. 
Considering Figure 7, it can be stated that PF9 is the compromised solutions in case of SAW and PF10 alternative was found to be a compromise solution in case of TOPSIS approach. It simply indicates that the contractor can pick up either PF9 or PF10. Tables 9 and 10 demonstrate the result matrix of the obtained rankings using TOPSIS as well as SAW approaches considering the optional weights. It expresses that in both the cases the cost is more valuable than the time of the project. Therefore, contractors or any other decision makers are paying more attention to the cost of the project.

Table 9. Result matrix of TOPSIS method using different weights.

\begin{tabular}{|c|c|c|c|c|c|c|c|c|c|c|}
\hline \multirow{3}{*}{$\begin{array}{l}\text { Sr. } \\
\text { No }\end{array}$} & \multirow{2}{*}{\multicolumn{2}{|c|}{ NDS-TLBO }} & \multicolumn{3}{|c|}{ Different weight preferences } & \multirow{3}{*}{$\begin{array}{l}\text { TOPSIS } \\
\text { Ranking }\end{array}$} & \multicolumn{3}{|c|}{ Equal weight } & \multirow{3}{*}{$\begin{array}{l}\text { TOPSIS } \\
\text { Ranking }\end{array}$} \\
\hline & & & \multirow{2}{*}{$\begin{array}{l}C_{\mathrm{t}}=0.001 \\
\mathrm{~S}_{i}^{+}\end{array}$} & \multicolumn{2}{|l|}{$C_{\mathrm{c}}=0.999$} & & \multirow{2}{*}{$\begin{array}{l}C_{\mathrm{t}}=0.5 \\
\mathrm{~S}_{i}^{+}\end{array}$} & \multicolumn{2}{|l|}{$C_{\mathrm{c}}=0.5$} & \\
\hline & Dur & Cost & & $\mathrm{S}_{i}^{-}$ & $\mathbf{C}_{i}$ & & & $\mathbf{S}_{i}^{-}$ & $\mathbf{C}_{i}$ & \\
\hline PF1 & 612 & 6192140 & 4887.39 & 4622.54 & 0.486 & 4 & 489.238 & 462.953 & 0.486 & 4 \\
\hline PF2 & 617 & 6184820 & 9509.94 & 0.01965 & 2.07E-06 & 10 & 951.947 & 17.691 & 0.018 & 10 \\
\hline PF3 & 590 & 6188690 & 7066.74 & 2443.20 & 0.256 & 8 & 707.550 & 244.575 & 0.257 & 8 \\
\hline PF4 & 588 & 6195910 & 2504.52 & 7005.42 & 0.736 & 3 & 251.251 & 701.244 & 0.736 & 3 \\
\hline PF5 & 591 & 6191490 & 5298.09 & 4211.85 & 0.442 & 5 & 530.549 & 421.616 & 0.443 & 5 \\
\hline PF6 & 586 & 6196840 & 1916.48 & 7593.46 & 0.798 & 2 & 192.654 & 760.106 & 0.798 & 2 \\
\hline PF7 & 592 & 6189140 & 6782.54 & 2727.4 & 0.286 & 7 & 679.085 & 273.034 & 0.287 & 7 \\
\hline PF8 & 589 & 6199870 & 0.01779 & 9509.94 & 0.999 & 1 & 16.019 & 951.948 & 0.983 & 1 \\
\hline PF9 & 617 & 6187390 & 7887.62 & 1622.32 & 0.170 & 9 & 789.552 & 163.355 & 0.171 & 9 \\
\hline PF10 & 616 & 6190570 & 5879.30 & 3630.64 & 0.381 & 6 & 588.520 & 363.830 & 0.382 & 6 \\
\hline
\end{tabular}

Performans Ranking

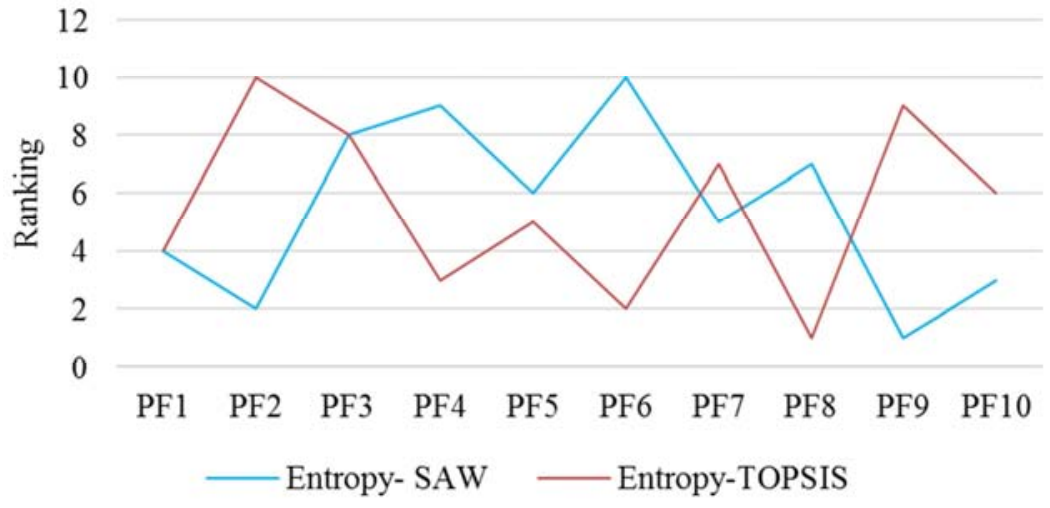

Figure 8. Performance ranking of the TOPSIS and SAW with equal weights.

As presented in Figure 8, PF8 was ranked as the first in the TOPSIS method while PF9 was ranked as the first in the SAW method. It is to mention that the adapted weight for both the approaches are equal. And the Pareto compromising solution remained same in case of SAW approach, however, it has changed in case of TOPSIS approach and become alternative PF8.

Table 10. Result matrix of SAW method using different weights.

\begin{tabular}{|c|c|c|c|c|c|c|}
\hline \multicolumn{3}{|c|}{ NDS-TLBO } & Sum of the Row & SAW Ranking & Sum of the Row & SAW Ranking \\
\hline \multirow{2}{*}{ P. Front } & \multirow{2}{*}{ Dur } & \multirow{2}{*}{ Cost } & \multicolumn{2}{|c|}{ Different weight preferences } & \multicolumn{2}{|l|}{ Equal weight } \\
\hline & & & $C_{\mathrm{t}}=0.001$ & $C_{\mathrm{c}}=0.999$ & $C_{\mathrm{t}}=0.5$ & $C_{\mathrm{c}}=0.5$ \\
\hline PF1 & 612 & 6192140 & 0.99874 & 5 & 0.9953247 & 4 \\
\hline PF3 & 590 & 6188690 & 0.99815 & 8 & 0.9772183 & 8 \\
\hline PF4 & 588 & 6195910 & 0.99931 & 3 & 0.9761798 & 9 \\
\hline PF5 & 591 & 6191490 & 0.99860 & 4 & 0.9782545 & 6 \\
\hline PF7 & 592 & 6189140 & 0.99823 & 7 & 0.9788753 & 5 \\
\hline PF8 & 589 & 6199870 & 0.99995 & 1 & 0.9773096 & 7 \\
\hline PF9 & 617 & 6187390 & 0.99798 & 9 & 0.9989935 & 1 \\
\hline PF10 & 616 & 6190570 & 0.99849 & 6 & 0.9984396 & 3 \\
\hline
\end{tabular}

\section{Conclusion and Recommendations}

In construction projects, the time and cost of completion of the construction period is a crucial aspect. The project owner or contractor would like to use less amounts of resources when performing the activities. Many studies have been conducted in the literature already to tackle with TCTP problems. These optimization algorithms could provide the Pareto-optimal solutions, however, they can only create the Pareto frontier at 
most without any further guidance to select the best choice among possible and available alternatives. The integration of MCDM methods with multi-objective optimization methods has been discussed in other fields such as water resource management, forest management, green energy planning, and etc. Hence, this study answers specifically to the question that why not using MCDM methods in construction project scheduling in the context of TCTPs. The framework proposed here, is able to establish a successful linkage between the optimization algorithms and MCDM methods. This enables the DMs to move into a further step where the decision making process of selecting the best alternative is carried out through an understanding framework.

The obtained results show that, first of all, the MCDM methods are highly efficient in ranking the project scheduling alternatives, and the DMs can be provided with higher level of confidence to implement the selected solution in real practice. Since, multi-objective optimization techniques, such as TLBO which are used here, are able to obtain a set of non-dominated solutions, being called as the Pareto-optimal solutions, there is the need to take one more step ahead to select the best optimal solution among the achieved Pareto-optimal set of solutions.

Firstly, the proposed TLBO multi-objective optimization algorithms with NSTLBO-II based procedure to solve TCTPs were coded in MATLAB R2013a. This problem with a total of $4.72 \times 10^{9}$ possible schedules is examined with a daily indirect cost of $\$ 1500$. In every 10 runs of the algorithm, exactly 105 Pareto solutions were identified; out of which 4 random Pareto solutions are picked up to be given and ranked. However, the utilized algorithm exhibits its competency and accuracy by exploring a tiny portion $\left[5640 / 4.72 \times 10^{9}=0.00012 \%\right]$ of the solution space. This reveals a remarkable reduction in number of function evaluations of administered algorithm comparing the literature.

In the medium scale example problem, the NDS-TLBO searched $162,180 \quad(=180 \times 450 \times 2+180)$ possible different schedules, only searching a negligible portion of the solution space $(162,180 / 1.4 \mathrm{E}+42)$. Population and number of iterations are adopted as 180 and 450 , respectively.

Secondly, the entropy approach is rather a straightforward MCDM method while the TOPSIS is too simple in terms of mathematical formulations. On the other hand, the SAW approach which is simpler in comparison with the TOPSIS method, has given a similar rank for the solutions. Thus, it is proposed that the TOPSIS approach can be more accurate approach in evaluating the solutions. Therefore, in TCTPs the TOPSIS approach can be efficiently used in comparison with the other methods although it is very simple.

Finally, the developed approaches can be made more efficient by employing fuzzy approach or hybrid algorithms which are more effective in avoiding local optimization. In addition, the approach can be extended with the Microsoft project interface as well as Primavera software.

\section{Conflict of Interest Statement}

The authors declare that they have no competing interests.

\section{References}

[1] Hwang, C. L., Yoon, K. (1981), "Multiple attribute decision making". Methods and applications a state of the art survey". Berlin-Heidelberg: Springer-Verlag.

[2] Chen, C. T. (2000), "Extensions of the TOPSIS for group decision-making under fuzzy environment". Fuzzy Sets and Systems, 114 (1): 1-9.

[3] Gumus, A. T. "Evaluation of hazardous waste transportation firms by using a two-step fuzzy-AHP and TOPSIS methodology". Expert Systems with Applications, 36: 40674074, (2009).

[4] Yong, D. (2006), "Plant location selection based on fuzzy TOPSIS". The International Journal of Advanced Manufacturing Technology, 28 (7-8): 839-844.

[5] Roy, B. (1991) "The outranking approach and the foundations of Electre methods". Theory and Decision, 31 (1): 49-73.

[6] Chaudhuri, S., \& Deb, K. (2010), “An interactive evolutionary multi-objective optimization and decision making procedure". Applied Soft Computing, 10 (2): 496-511.

[7] Bazargan-Lari, M. R. (2014), “An evidential reasoning approach to optimal monitoring of drinking water distribution systems for detecting deliberate contamination events". Journal of Cleaner Production, 78 (1): 1-14.

[8] Monghasemi, S., Nikoo, M. R., Fasaee, M. A. K., \& Adamowski, J. (2015), “A Novel Multi Criteria Decision Making Model for Optimizing Time-Cost-Quality Trade-off Problems in Construction Projects". Expert Systems with Applications, 42 (6): 3089-3104.

[9] Perera, A., Attalage, R., Perera, K., \& Dassanayake, V. (2013), "A hybrid tool to combine multi-objective optimization and multi-criterion decision making in designing standalone hybrid energy systems". Applied Energy, 107: 412-425.

[10] Eirgash, M. A., and Dede, T. (2018). "A multi-objective improved teaching learning-based optimization algorithm for time-cost trade-off problems." J. Constr. Eng. Manage. Innovation, 1 (3): 118-128.

[11] Toğan, V., and Eirgash, M. A. (2019). "Time-cost trade-off optimization of construction projects using teaching learning-based optimization.” KSCE J. Civ. Eng., 23 (1), 10-20.

[12] Colorni, A., Dorigo, M., Maniezzo, V., \& Trubian, M. “Ant system for job-shop scheduling". Belgian Journal of Operations Research, Statistics and Computer Science, 34: 39-53 (1994).

[13] Ng, T. S., \& Zhang, Y. (2008), "Optimizing construction time and cost using ant colony optimization approach". Journal of Construction Engineering and Management, 134 (9): 721-728.

[14] Mohammad Ammar Al-Zarrad and Daniel Fonseca (2018) "A New Model to Improve Project Time-Cost Trade-Off in Uncertain Environments", Contemporary Issues and Research in Operations Management, DOI: 10.5772/intechopen.74022.

[15] Eirgash, M. A. Pareto-Front Performance of Multiobjective Teaching Learning Based Optimization Algorithm on Time-Cost Trade-Off Optimization Problems. Master of Science Thesis, Karadeniz Technical University, (2018), Turkey. 
[16] Rao, R. V., \& Patel, V. (2011). "Multi-objective optimization of combined Brayton and inverse Brayton cycles using advanced optimization algorithms". Engineering Optimization, 44 (8): 965-983.

[17] Eirgash, M. A., Toğan, V., and Dede, T. (2019). "A multi-objective decision-making model based on TLBO for the time-cost trade-off problems." Struct. Eng. Mech., 71 (2), $139-151$.

[18] Feng, C.-W., Liu, L., \& Burns, S. A. (1997), "Using genetic algorithms to solve construction time-cost trade-off problems". Journal of Computing in Civil Engineering, 11 (3): 184-189. 